OPEN ACCESS

Edited by: Wen Nie,

Jiangxi University of Science and

Technology, China

Reviewed by:

Zhen Huang,

Jiangxi University of Science and

Technology, China

Yanxu Zhang,

China University of Mining and

Technology, China

Weiqiang Zhang,

China University of Mining and

Technology, China

*Correspondence:

Xiaoshen Xie

xxswpp0816@163.com

Enke Hou

houek@xust.edu.cn

Specialty section:

This article was submitted to

Geohazards and Georisks,

a section of the journal

Frontiers in Earth Science

Received: 30 October 2021

Accepted: 29 November 2021

Published: 21 January 2022

Citation:

Xie $X$, Hou E, Long T, Feng $D$, Hou $P$, Wei Q, Li Y and Liu J (2022) Study on

Evaluation and Prediction of the Degree of Surface Damage Caused by

Coal Mining.

Front. Earth Sci. 9:805248. doi: 10.3389/feart.2021.805248

\section{Study on Evaluation and Prediction of the Degree of Surface Damage Caused by Coal Mining}

\author{
Xiaoshen Xie ${ }^{1,2 *}$, Enke Hou ${ }^{1,2 *}$, Tianwen Long ${ }^{1,2}$, Dong Feng ${ }^{1,2}$, Pengfei Hou ${ }^{1,2}$, Qiming Wei ${ }^{3}$, \\ Yang $\mathrm{Li}^{4}$ and Jiangbin $\mathrm{Liu}^{4}$
}

${ }^{1}$ College of Geology and Environment, Xi'an University of Science and Technology, Xi'an, China, ${ }^{2}$ Shaanxi Provincial Key Laboratory of Geological Support for Coal Green Exploitation, Xi'an, China, ${ }^{3}$ Shicaocun Coal Mine of Ningxia Coal Industry Co., Ltd. of National Energy Group, Lingwu, China, ${ }^{4}$ Yangchangwan Coal Mine of Ningxia Coal Industry Co., Ltd. of National Energy Group, Lingwu, China

Surface damage caused by coal mining is one of the problems perplexing ecological environment restorations in coal mining areas. Accurately evaluating and predicting the degree of surface damage induced by coal mining with reasonable and correct indexes are of great significance to the restoration and treatment of the ecological environment. In this paper, these methods including the unmanned aerial vehicle aerial photography and manual measurement were used to investigate the development characteristics of surface damage caused by $2^{\#}$ coal seam mining in Yangchangwan Coal Mine. The results showed that with the change of mining conditions, the characteristics of surface cracks change obviously, which can be adopted to indicate the degree of surface damage. Thus, based on the results of the investigation, the classification standard of surface damage degree was established based on the evaluation indexes including density of crack, drop height of surface crack, crack width, maximum surface subsidence, and geological disaster caused by cracks and the damage characteristics of buildings. The evaluation method and process of surface damage degree also were given. Based on the ratio of the buried depth to the thickness of the coal seam $(\mathrm{H} / \mathrm{M})$, ratio of the thickness of overlying bedrock to the thickness of the coal seam, the thickness of loose layers (Ms), geomorphology, distance to faults, and distance to folds, the prediction model of surface damage degree was built on the GIS platform. The weight coefficient of each prediction index was obtained by the analytic hierarchy process (AHP) method. The surface damage degree map of $2^{\#}$ coal seam in Yangchangwan Coal Mine was divided into four classes: very minor, minor, moderate, and serious, which provides a relatively applicable method for the prediction of surface damage degree in Yangchangwan Coal Mine and its adjacent mining areas.

Keywords: ground collapse, surface damage, coal mining, GIS, AHP, Yangchangwan coal mine

\section{INTRODUCTION}

At present, the proportion of coal consumption to total primary energy consumption began to decline after implementation of the coal industry rationalization action by the Chinese government (Wang et al., 2020; Yan et al., 2018; Xie et al., 2021). But coal still plays an important role in the development of regional economy, especially the western China economy (Yan et al., 2021; Zhu et al., 2018). Undoubtedly, exploitation of coal resources will do harm to the environment of the ground 
surface, such as exhaustion of groundwater resources, death of vegetation, cracking of the land, and damage to surface structures, such as railroad tracks, roads, and buildings. Moreover, with the increase of scale and intensity of coal resources, the environmental problems caused by mining will be more serious (Zeng et al., 2020; Xu Y. et al., 2019; Fan et al., 2017; Fan et al., 2015; Huang et al., 2013; Bell et al., 2000). Thus, clearly grasping the distribution of ground subsidence and accurately evaluating the susceptibility of ground subsidence is the prerequisite for ensuring the safety of the workers and restoration and treatment of the environment.

Evaluation is a description and characterization of objects that have emerged (Djamaluddin et al., 2011; Si et al., 2010). Some indicators including water (Guo, et al., 2019; Xiao et al., 2020; Zeng et al., 2020), landform (Hu Z. et al., 2014a), landscape (Xu J. et al., 2019; Quanyuan et al., 2009), geological disaster (Shao, 2019), and building damage (Djamaluddin, et al., 2011; Malinowska and Hejmanowski, 2010) have been used to evaluate the degree of ground collapse. In addition, Yu et al. divided the land subsidence damage into four grades using the surface subsidence (Yu, et al., 2008). Youfeng Zou et al. divided the land damage into six grades according to the stable ground slope, the relationship between surface inclination deformation, and soil erosion (Zou, et al., 2003). Xiaojing Li et al. used the surface crack, surface subsidence and collapse crater, and additional gradient to classify the degree of land damage caused by coal mining (Li, et al., 2012). Zishao Zhang et al. determined the evaluation criteria for the degree of geological environment induced by coal mining using the horizontal deformation, the deformation of slope, and curvature (Zhang and Sui, 2017).

The above results have laid the foundation for the in-depth study of the evaluation of the degree of surface damage. However, it was impractical to use the horizontal movement deformation and tilt deformation as an index to evaluate the degree of surface damage because not all working faces have these two values that need to be measured for a long time, and the cost is relatively high to obtain these two parameters. In addition, for the workers in the coal mine, the evaluation standard established in the above research is too complex to be applied in practical work. For these reasons, selecting intuitive, convenient, and easy to obtain parameters as the index to evaluate the degree of surface damage caused by working in face mining is one of the problems to be solved in the paper.

Generally, surface damage can be decreased to a certain extent by predicting the degree of surface damage. In recent years, several models including the analytic hierarchy process (AHP) (Rezaei, et al., 2020; Zhang, et al., 2011), artificial neural network (ANN) (Lee, et al., 2012; Kim, et al., 2009), rough set (RS) (Feng and Luo. 2016), and other methods in tandem with GIS were adopted to evaluate the ground subsidence susceptibility caused by coal mining by some experts. But there are two shortcomings. One is that the above research methods or models were used to predict the ground subsidence susceptibility rather than the degree of surface damage, the other was that the indicators used for prediction were not consistent with parameters of coal mining such as mining thickness of coal seam, depth of coal seam, bedrock thickness, thickness of soil layer, and so on. Therefore, using the reasonable prediction model to predict the degree of surface damage caused by coal mining with appropriate factors is another problem to be solved in this paper.

In order to complete the research content, Yangchangwan Coal Mine was taken as the study area and the UAV remote sensing and field investigation were applied to investigate the ground collapse caused by working face mining. According to the survey results, the evaluation factors of surface damage were determined, and then the surface damage level was divided. Combined with the coal mining information and geological information of the working face, the prediction model of surface damage could be established with the appropriate index of surface damage under the GIS platform.

\section{GENERAL SITUATION OF THE STUDY AREA AND INVESTIGATION METHOD}

\section{General Situation of the Study Area}

Yangchangwan Coal Mine chosen as the study area is located in Ningxia Province, China, within latitudes $37^{\circ} 54^{\prime} 49^{\prime \prime} \mathrm{N}$ to $38^{\circ} 02^{\prime}$ $27^{\prime \prime} \mathrm{N}$, and longitudes $106^{\circ} 33^{\prime} 46^{\prime \prime} \mathrm{E}$ to $106^{\circ} 39^{\prime} 49^{\prime \prime} \mathrm{E}$ (Figure 1). The study area belongs to Ningxia Coal Industry Group, which is an important mining area in the coal base located in the east of Ningxia. The coal mine's length is about $12.8 \mathrm{~km}$ from north to south, and its width is approximately $9.8 \mathrm{~km}$, the overall area is about $58.21 \mathrm{~km}^{2}$. Land types in the study area are mainly grass, bare land, and residential areas. The altitude ranges from $1,320.25 \mathrm{~m}$ to $1,497.69 \mathrm{~m}$ and increases from north to south. The surface is mainly covered by the loess and wind aeolian loose layer, and bedrock appears sporadically.

As can be seen from Figure 2, the strata, from old to new, in the coal mine are mainly Triassic, Jurassic, Cretaceous, and Quaternary. The Yanan formation of Jurassic is the main coal bearing strata in the area, with an average thickness of $91.47 \mathrm{~m}$, which contains 32 layers of coal seam. Among these coal seams, the stable $2^{\#}$ coal seam with dip angle ranges from $5^{\circ}$ to $28^{\circ}$ is being mined. The occurrence thickness of $2^{\#}$ coal seam ranges from 4.73 to $10.66 \mathrm{~m}$ ( $7.80 \mathrm{~m}$ averagely), and the mining depth ranges from 50 to $1,300 \mathrm{~m}$ and decreases from north to south. The thickness of the surface loose layer ranges from 1.65 to $36.95 \mathrm{~m}$, and the average thickness is $10.17 \mathrm{~m}$. There are about 23 faults in the study area, of which 15 faults are normal and eight faults are reverse. In addition, there are nine folds in the region.

\section{Methods for Investigation of Surface Damage}

Ground collapse, which includes surface crack, surface subsidence, collapse, and landslide caused by coal mining, is the main form of surface damage and also is the object of this investigation. In order to accurately obtain the surface damage date of each working face, UAV and manual monitoring were carried out (Figure 3), and the indexes of UAV are shown in Table 1. 


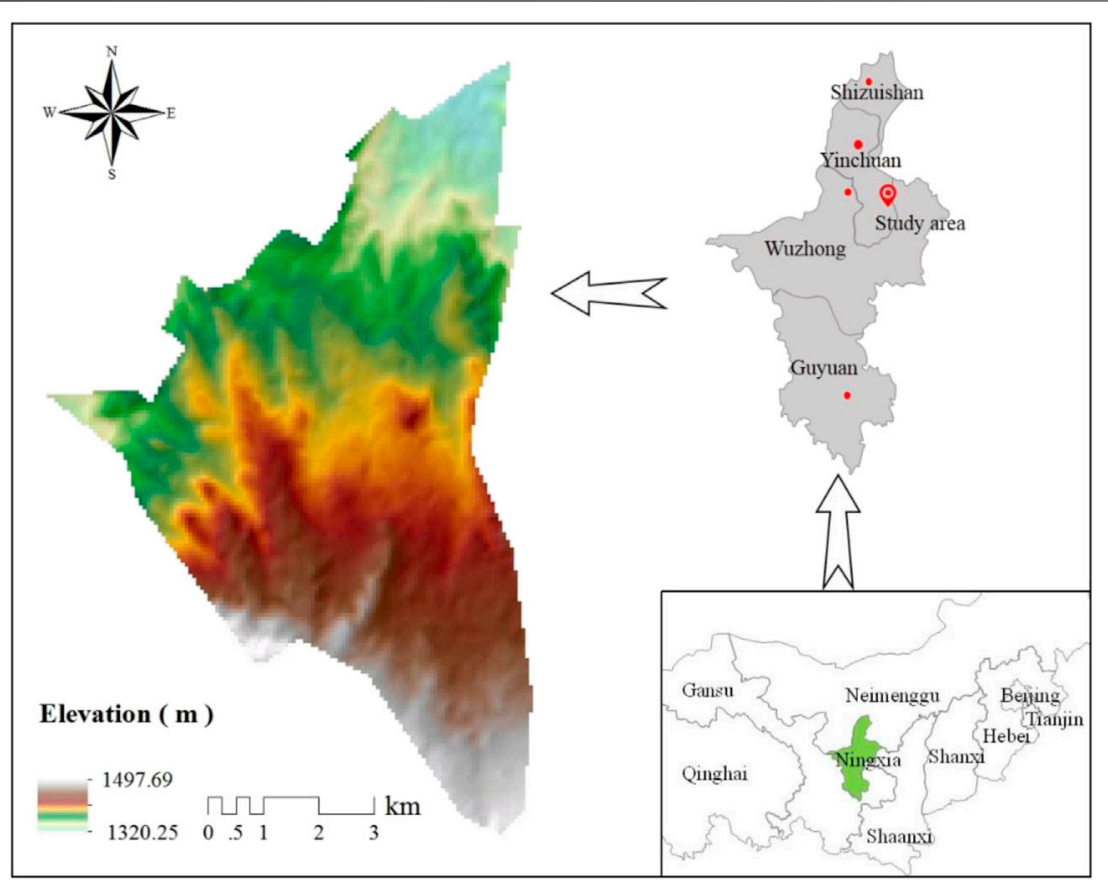

FIGURE 1 | Study area location.

\section{EVALUATION OF SURFACE DAMAGE DEGREE}

\section{Results of Investigation on Surface Damage}

A total of 10 working faces were investigated in the study area (Figure 4). The surface damage caused by 120,211 and 120,209 working face mining had been repaired. Thus, there is a lack of data on surface damage induced by 120,211 and 120,209 working face. The investigation results of the remaining working faces are shown in Table 2.

The surface damage caused by 110,207 working face located in the north of the study area was serious. The density of surface cracks was $181 \mathrm{l} / \mathrm{km}^{2}\left(l / \mathrm{km}^{2}\right.$ indicates the number of cracks in the $1 \mathrm{~km}^{2}$ area), the maximum width and the maximum drop height of surface cracks were 150 and $160 \mathrm{~cm}$, respectively. A collapse groove with a width of $4.0 \mathrm{~m}$ was developed on the surface above the working face. Since the surface subsidence had not been measured in the mining process of the working face, there is no way to obtain the maximum surface subsidence. In addition, the number of associated disasters caused by the working face was zero, and there were no roads and buildings above the working face.

The density of surface cracks, the maximum width, and the maximum drop height caused by 110,201 working face were $280 \mathrm{l} / \mathrm{km}^{2}, 76 \mathrm{~cm}$, and $45 \mathrm{~cm}$, respectively. There was no collapse groove, associated disasters, roads and buildings above the working face, and the surface subsidence was not measured in the mining process.

The density of surface cracks, the maximum width, and the maximum drop height caused by 120,215 working face were
$206 \mathrm{l} / \mathrm{km}^{2}, 34 \mathrm{~cm}$, and $10 \mathrm{~cm}$, respectively. There was no collapse groove, associated disasters, or roads and buildings above the working face. The maximum subsidence was not obtained.

In 120,210 working face, the surface damage characteristics are more obviously caused by coal mining. The density of surface cracks is $145 \mathrm{l} / \mathrm{km}^{2}$, the width is generally less than $30 \mathrm{~cm}$, and the maximum drop height was $18 \mathrm{~cm}$. There was no measured data on surface subsidence and buildings. However, a road in the working face was cracked by coal mining.

The 130,204 working face was located in the south of the mine field. The surface damage caused by 130,204 working face was minor, the density of surface cracks is $41 \mathrm{l} / \mathrm{km}^{2}$, and the maximum drop height and width of surface cracks were 8 and $15 \mathrm{~cm}$. There was no collapse groove development in the working face. In addition, there are no roads and buildings in the working face.

According to the survey results, the density of the surface cracks was $104 \mathrm{l} / \mathrm{km}^{2}$, the maximum drop height and width of the surface cracks caused by 160,203 working face were 11 and $30 \mathrm{~cm}$, respectively. After mining, there were no collapse groove and associated disasters on the surface.

The density of surface cracks caused by 120,212 working face was $65 \mathrm{l} / \mathrm{km}^{2}$ and all surface cracks have no drop height, the maximum width was $5 \mathrm{~cm}$. Furthermore, the road in the working face was intact.

As similar to 120,212 working face, the surface damage induced by 160,202 working face was very minor. The surface crack was the only form of surface damage. The density of surface cracks was $61 \mathrm{l} / \mathrm{km}^{2}$, the maximum drop height and width were 5 and $21 \mathrm{~cm}$, respectively. 


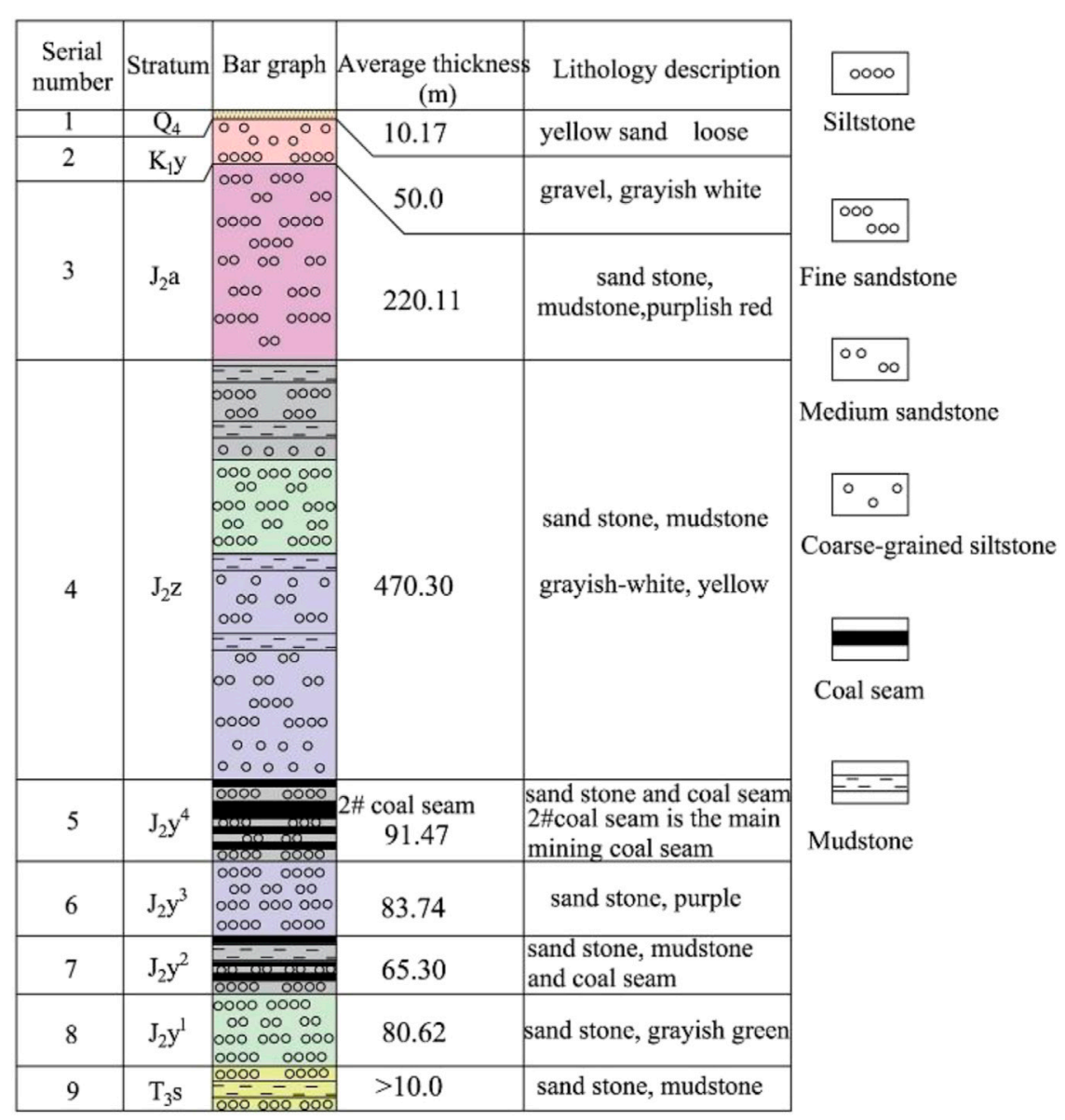

FIGURE 2 | The overburden strata histogram of the $2^{\#}$ coal seam.

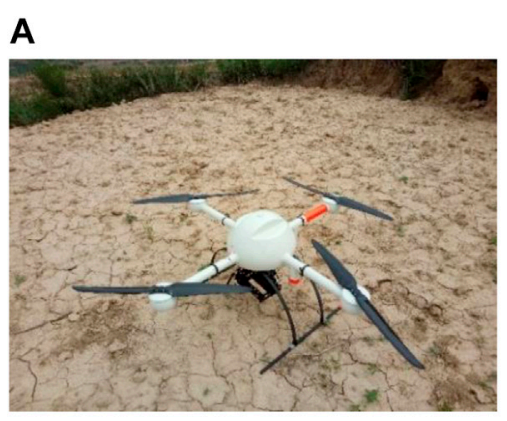

the UAV(Md4-1000)

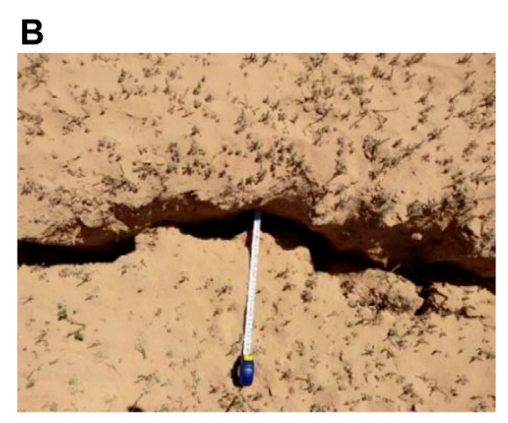

manual monitoring

FIGURE 3 | Methods for investigation of surface damage. (A) The UAV(Md4-1,000). (B) Manual monitoring.

\section{CLASSIFICATION OF SURFACE DAMAGE DEGREE OF WORKING FACE}

According to the investigation results of surface damage caused by working face, the surface crack was the most intuitive and convenient parameter to characterize the surface damage degree. Based on the combination of actual management experience and the investigation results, the crack density, maximum drop height, maximum width, maximum subsidence, associated disasters, and other features were taken as the classification standard of the surface damage degree, and the degree of surface damage was divided into four grades, which were serious, moderate, minor, and very minor (Table 3 ). 
TABLE 1 I The indexes of UAV.

Performance of UAV (Md4-1,000)

\begin{tabular}{llll}
\hline Climbing rate & $7.5 \mathrm{~m} / \mathrm{s}$ & Cruising speed & $15.0 \mathrm{~m} / \mathrm{s}$ \\
Maximum power & $1,000 \mathrm{~W}$ & Weight of the UAV & $2,650 \mathrm{~g}$ \\
Flight time & $<50 \mathrm{~min}$ & Load & $2000 \mathrm{~g}$ \\
Flight radius & $5,000 \mathrm{~m}$ & Flight altitude & $1,000 \mathrm{~m}$ \\
Remote control distance & $5,000 \mathrm{~m}$ & Wind resistance & $<12 \mathrm{~m} / \mathrm{s}$
\end{tabular}

\section{EVALUATION RESULT OF SURFACE DAMAGE DEGREE OF WORKING FACE}

The evaluation process of the surface damage degree is shown in Figure 5. The first step was selection of target working face. The second step was to investigate the surface damage characteristics of the target face. The third step was to evaluate the index grade according to Table 3. The last step was to take the highest grade of the index as the grade of the

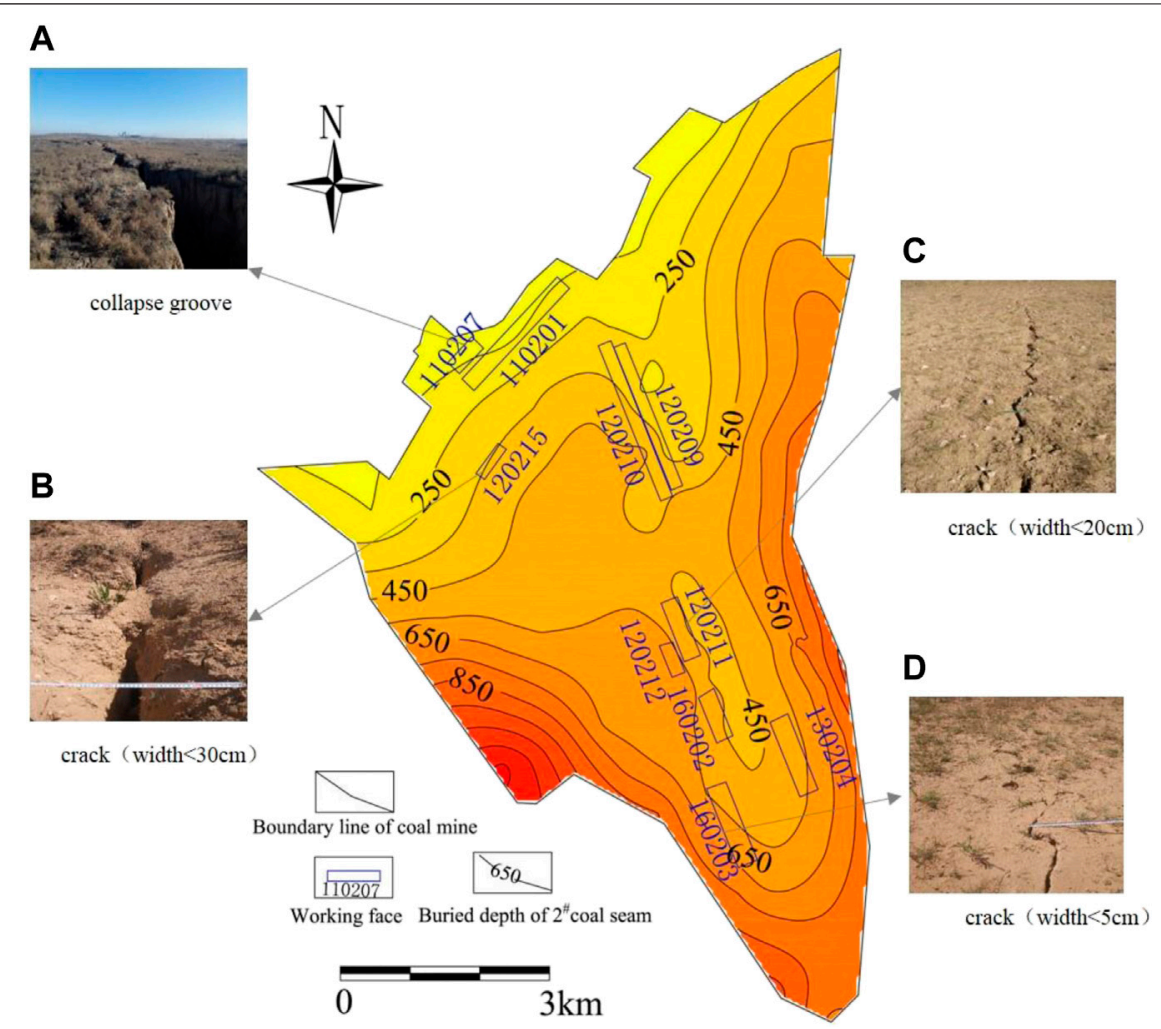

FIGURE 4 | (A) collapse groove; (B) Crack with a width less than $30 \mathrm{~cm}$; (C) Crack with a width less than $20 \mathrm{~cm}$; (D) Crack with a width less than $5 \mathrm{~cm}$.

TABLE 2 | Results of surface damage.

\begin{tabular}{|c|c|c|c|c|c|c|c|c|}
\hline \multirow[t]{2}{*}{ Name } & \multicolumn{3}{|c|}{ Surface crack } & \multirow{2}{*}{$\frac{\text { Collapse }}{\text { Maximum width }}$} & \multirow{2}{*}{$\begin{array}{l}\text { Maximum subsidence } \\
\text { (m) }\end{array}$} & \multirow{2}{*}{$\begin{array}{c}\text { Number of } \\
\text { associated disasters }\end{array}$} & \multicolumn{2}{|c|}{ Other features } \\
\hline & $\begin{array}{l}\text { Crack density } \\
\left(/ / \mathbf{k m}^{2}\right)\end{array}$ & $\begin{array}{l}\text { Maximum drop } \\
\text { (cm) }\end{array}$ & $\begin{array}{l}\text { Maximum width } \\
(\mathrm{cm})\end{array}$ & & & & Roads & Buildings \\
\hline 110,201 & 280 & 45 & 76 & 0 & No data & 0 & No roads & No buildings \\
\hline 120,215 & 206 & 10 & 34 & 0 & No data & 0 & No roads & No buildings \\
\hline 120,210 & 145 & 18 & 30 & 0 & No data & 0 & Cracked & No buildings \\
\hline 120,212 & 65 & 0 & 5 & 0 & No data & 0 & Intact & Cracked \\
\hline 160,202 & 61 & 5 & 21 & 0 & No data & 0 & No roads & No buildings \\
\hline
\end{tabular}


TABLE 3 | The degree of surface damage.

\begin{tabular}{|c|c|c|c|c|c|c|c|}
\hline \multirow{2}{*}{$\begin{array}{l}\text { Surface damage } \\
\text { degree }\end{array}$} & \multirow{2}{*}{ 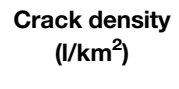 } & \multirow{2}{*}{$\begin{array}{l}\text { Maximum drop } \\
\text { (cm) }\end{array}$} & \multirow{2}{*}{$\begin{array}{l}\text { Maximum width } \\
\text { (cm) }\end{array}$} & \multirow{2}{*}{$\begin{array}{l}\text { Maximum subsidence } \\
\text { (m) }\end{array}$} & \multirow[t]{2}{*}{ Associated disasters } & \multicolumn{2}{|c|}{ Other features } \\
\hline & & & & & & Roads & Buildings \\
\hline Very minor & $<20$ & 0 & $<1.0$ & $<0.1$ & 0 & Intact & Intact \\
\hline Moderate & $100 \sim 300$ & $5.0 \sim 30$ & $1.0 \sim 50$ & $1.0 \sim 3.0$ & $10 \sim 50$ & Cracked & Cracked \\
\hline Serious & $>300$ & $>30$ & $>50$ & $>3.0$ & $>50$ & Severely cracked & Severely cracked \\
\hline
\end{tabular}

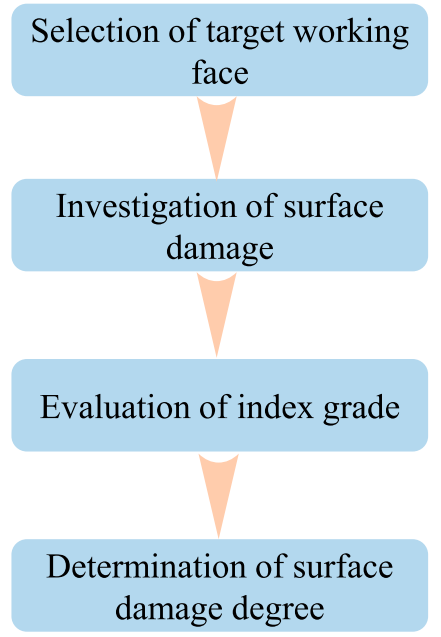

FIGURE 5 | Evaluation process of the surface damage degree.

TABLE 4 | The degree of surface damage of the working face in the study area.
The name of the working face

110,207

110,201

120,215

120,210

130,204

120,212

160,202
160,203
The degree of surface damage

Serious

Serious

Moderate

Moderate

Moderate

Moderate

Minor

Moderate surface damage degree of the working face according to the evaluation results of the index.

According to the above evaluation process and combined with the formulated level of the surface damage degree, the evaluation of the surface damage degree of 8 working faces in the study area was completed, and the results were as follows: the degree of surface damage caused by 110,207 working face and 110201working face were serious, the degree of surface damage induced by $120,215,120,210,130,204,160,203$, and 160,202 working face mining were moderate, and that induced by 120,212 the degree of surface damage was minor (Table 4).

\section{PREDICTION OF SURFACE DAMAGE}

\section{Factors of the Surface Damage Degree}

According to previous literature and surface damage of the study area, 6 conditioning factors were selected, including the ratio of the buried depth to the thickness of the coal seam $(\mathrm{H} / \mathrm{M})$, ratio of the thickness of overlying bedrock to the thickness of the coal seam, the thickness of the loose layer (Ms), geomorphology, distance to faults, and distance to folds in the study. All above factor maps were converted into raster format with a spatial resolution of $20 \times 20 \mathrm{~m}$.

The actual mining thickness of the coal seam is generally less than or equal to the thickness of the coal seam, which is positively correlated with the degree of surface damage induced by coal mining. In general, the working face with large mining thickness has a large goaf after mining, which provides sufficient activity space for the overlying strata, which leads to the stronger disturbance to the surface. The buried depth of the coal seam is negatively correlated with the degree of surface damage. Generally, the greater the buried depth of the coal seam, the longer the time for the disturbance caused by mining to be transmitted to the surface, the more attenuation of the disturbance, and the more minor the surface damage. Therefore, in the study the ratio of the buried depth to the thickness of the coal seam $(\mathrm{H} / \mathrm{M})$ was taken as a factor to predict the degree of surface damage caused by coal mining. The ratio $(\mathrm{H} / \mathrm{M})$ was reclassified into four classes (Figure 6A).

As a parameter negatively related to the degree of surface damage caused by coal mining, the thickness of overlying bedrock can prolong the time for the deformation to extend to the surface, which reduces the degree of surface damage induced by coal mining. Thus, in the present study, the ratio of the thickness of overlying bedrock to the thickness of the coal seam $(\mathrm{Hj} / \mathrm{M})$ was reclassified into four categories: < 45, 45-70, 70-95, >95 (Figure 6B).

The loose layer refers to the sedimentary strata in Quaternary and Neogene, which has great influence on the characteristics of surface movement, especially horizontal movement and horizontal deformation. Commonly, the greater the thickness of the loose layer, the more uniform the surface deformation and the smaller the less developed the surface cracks. The thickness of the loose layer (Ms) of the study area ranged from 0 to $56 \mathrm{~m}$ and was divided into four classes (Figure 6C).

Geomorphology is also an important factor affecting the degree of surface damage caused by coal mining. Generally, the surface damage induced by coal mining under the loess 

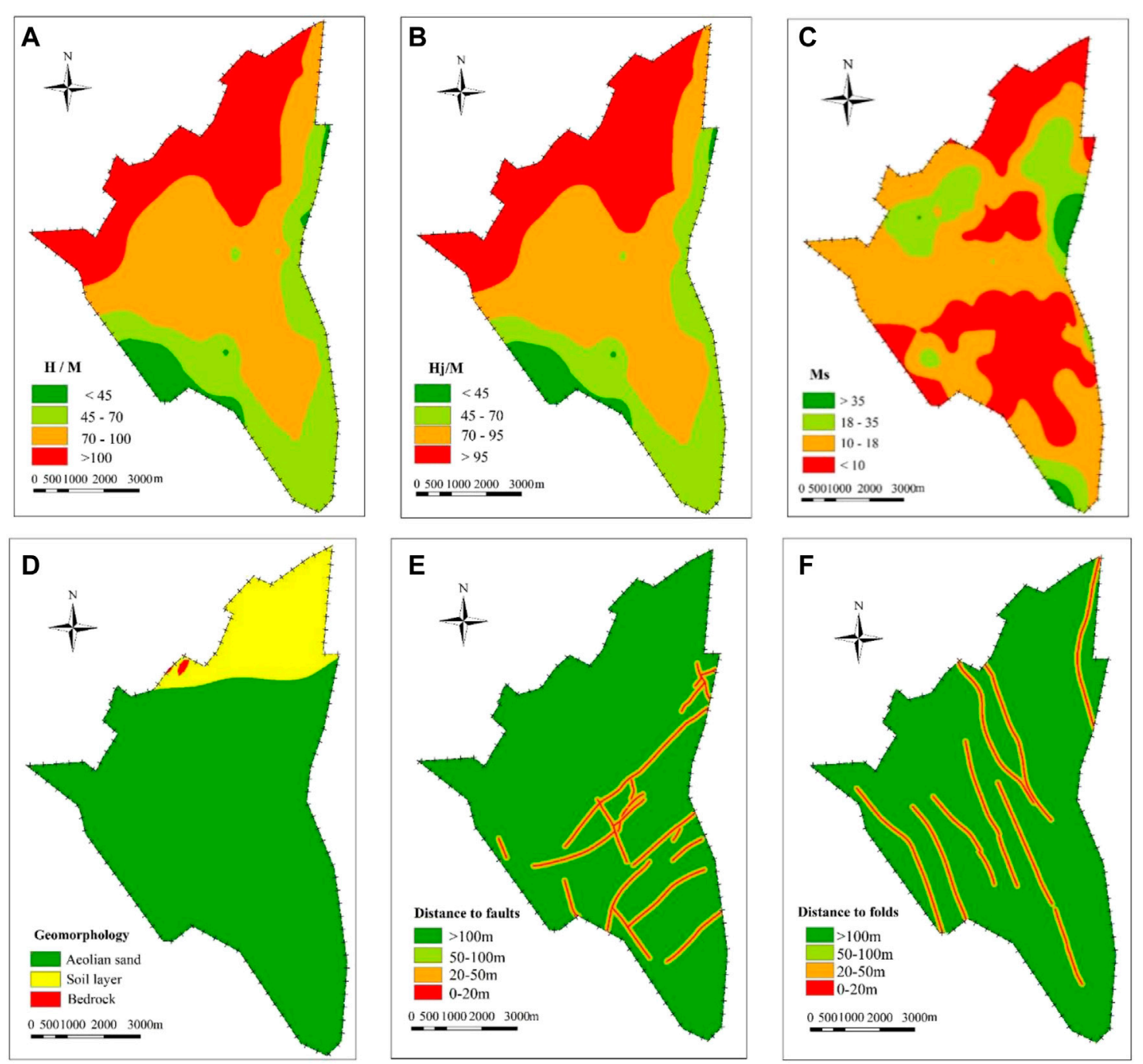

FIGURE 6 | Study area thematic area: (A) H/M, (B) Hj/M, (C) Ms, (D) geomorphology, (E) distance to faults, and (F) distance to folds.

gully landform is more serious than that under the sandy region. In this study, the geomorphology was reclassified into three categories: aeolian sand, soil layer, and bedrock (Figure 6D). Generally, the degree of surface damage caused by coal mining under bedrock was greatest, and the degree of surface damage was least under aeolian sand.

As an independent index, the fault restricts the surface damage by means of affecting the mechanical property of the bedrock and the slip of faults along the cross-section. In general, the surface damage caused by mining of the working face near the geological fault is relatively serious because the surrounding rock strength decreases, and fault slip due to tectonic break. In this study, the fault buffers were reclassified into four categories to produce the map of distance to the faults (Figure 6E).

In general, mining leads to the superposition of overlying rock and surface movement caused by folds, and it is easy to appear as discontinuous movement and deformation and increase the amount of subsidence on the axis of folds. Thus, the surface damage caused by coal mining in the geological fold areas is more serious. Like distance to faults, fourfold buffers were created (Figure 6F).

\section{METHODOLOGY OF AHP}

In order to accurately predict the degree of surface damage by coal mining, the analytic hierarchy process (AHP) method, which is a multi-criteria decision making (MCDM) and was put forward by Saaty (1980), and was applied in the essay and was divided into four steps (Saaty, 1980; Durmuşoğlu., 2018; Gnanavelbabu and Arunagiri, 2018).

In the current study, building an AHP model is the first step. In this study, occurrence conditions of the coal seam are subdivided into the ratio of the buried depth to the thickness of coal seam $(\mathrm{H} / \mathrm{M})$ and the ratio of the thickness of overlying bedrock to the thickness of the coal seam $(\mathrm{Hj} / \mathrm{M})$. The geological 


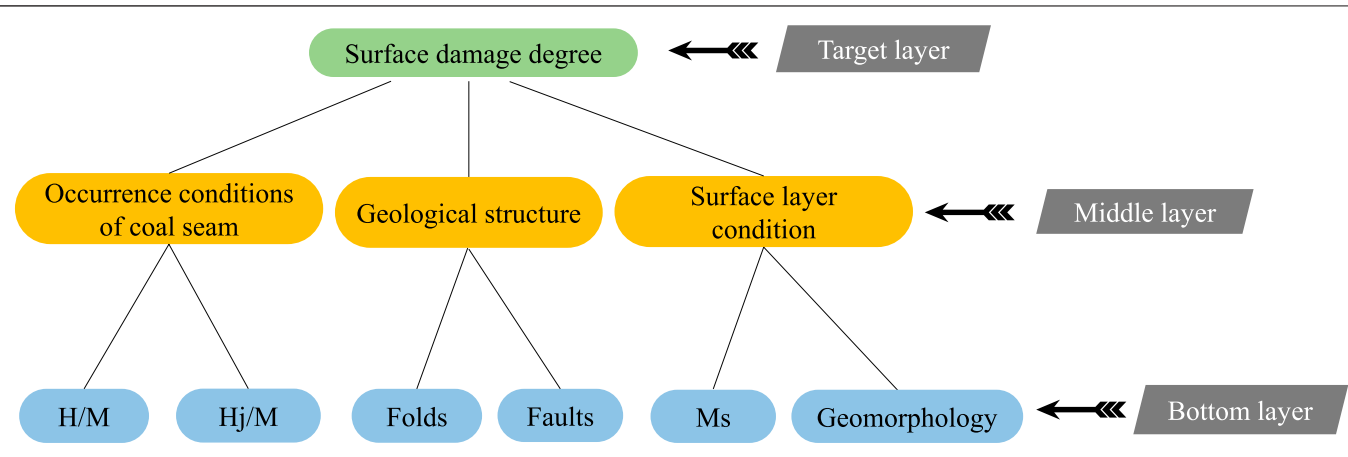

FIGURE 7 | AHP model.

TABLE $\mathbf{5}$ | Weights of factors for prediction of the degree of surface damage.

\begin{tabular}{|c|c|c|c|c|c|c|}
\hline \multirow[t]{2}{*}{ Factors } & \multicolumn{2}{|c|}{$\begin{array}{c}\text { Conditions of the coal } \\
\text { seam }\end{array}$} & \multicolumn{2}{|c|}{ Geological structure } & \multicolumn{2}{|c|}{ Surface layer condition } \\
\hline & $H / M$ & $\mathrm{Hj} / \mathrm{M}$ & $\begin{array}{l}\text { Distance to } \\
\text { faults }\end{array}$ & $\begin{array}{l}\text { Distance to } \\
\text { folds }\end{array}$ & Geomorphology & Ms \\
\hline Weights & 0.271 & 0.453 & 0.052 & 0.031 & 0.072 & 0.121 \\
\hline
\end{tabular}

structure condition is based on the fault and the fold. The surface layer condition is subdivided into two indexes such as thickness of loose layer (Ms) and geomorphology. The AHP model which was built in the previous step was divided into three layers, the degree of surface damage is the target layer (A layer). Occurrence conditions of the coal seam, the geological structure condition, and the surface layer condition belong to the middle layer (B layer). The bottom layer (C layer) consists of six factors derived from occurrence conditions of the coal seam, the geological structure condition, and the surface layer condition (Figure 7).

The second step was to construct a judgment matrix for the degree of surface damage caused by coal mining, which was used to verify the AHP model constructed in the first step by comparing the consistency parameters. The judgment matrix for the degree of surface damage is as follows:

$$
\mathrm{A}=\left[\begin{array}{cccccc}
\mathrm{C}_{11} & \mathrm{C}_{12} & \mathrm{C}_{13} & \mathrm{C}_{14} & \mathrm{C}_{15} & \mathrm{C}_{16} \\
\mathrm{C}_{21} & \mathrm{C}_{22} & \mathrm{C}_{23} & \mathrm{C}_{24} & \mathrm{C}_{25} & \mathrm{C}_{26} \\
\vdots & \vdots & \vdots & \vdots & \vdots & \vdots \\
\mathrm{C}_{61} & \mathrm{C}_{62} & \mathrm{C}_{63} & \mathrm{C}_{64} & \mathrm{C}_{65} & \mathrm{C}_{66}
\end{array}\right]
$$

As the next step, sub-criteria under each main criterion are compared two by two by three experts by using Mesh cade software, and then the weight coefficient of each index was calculated. Table 5 indicates the weights for all factors, the sum of factor weights was 1 , and the most important factor for the degree of surface damage is "ratio of the thickness of overlying bedrock to the thickness of the coal seam $(\mathrm{Hj} / \mathrm{M})$ " which weight was 0.465 . The least important factor was folds which weight was 0.051 . Finally, the key of the AHP method is the consistency test, which was adopted to examine the rationality of the judgment that was constructed in the previous step. As shown in Table 5, the consistency index of the judgment matrix $\left(C_{R}\right)$ is
$0.063<0.1$, which indicated that the judgment matrix was reasonable.

$$
\mathrm{C}_{\mathrm{R}}=0.0623
$$

\section{Prediction Model of the Degree of Surface Damage}

Based on the above analysis and the weight of each factor, the prediction model of the degree of surface damage was established, as follows:

$$
\begin{aligned}
& W=\sum_{i=1}^{n} W_{i} \times f_{i}(x, \mathrm{y})=0.271 \times f_{1}(\mathrm{x}, \mathrm{y})+0.453 \times f_{2}(\mathrm{x}, \mathrm{y})+0.052 \times f_{3}(\mathrm{x}, \mathrm{y})+ \\
& 0.031 \times f_{4}(\mathrm{x}, \mathrm{y})+0.048 \times f_{5}(\mathrm{x}, \mathrm{y})+0.145 \times f_{6}(\mathrm{x}, \mathrm{y})
\end{aligned}
$$

where $\mathrm{W}$ is the value indicating the degree of surface damage by coal mining, higher values indicate serious surface damage. $w_{i}$ is the weight value of the i factor and $\mathrm{fi}(\mathrm{x}, \mathrm{y})$ is the normalized value of the $\mathrm{i}$.

\section{RESULTS OF THE DEGREE OF SURFACE DAMAGE}

First, the above factors of surface damage were normalized. The positive factors were normalized by Eq. 1, and the negative factors were normalized by Eq. 2. However, the geomorphology that cannot be normalized by the formula was normalized by the reassignment method. The aeolian sand area was assigned as 0.4 , the soil area was assigned as 0.6 , and 1.0 was assigned to the bedrock area.

Equation 1: 


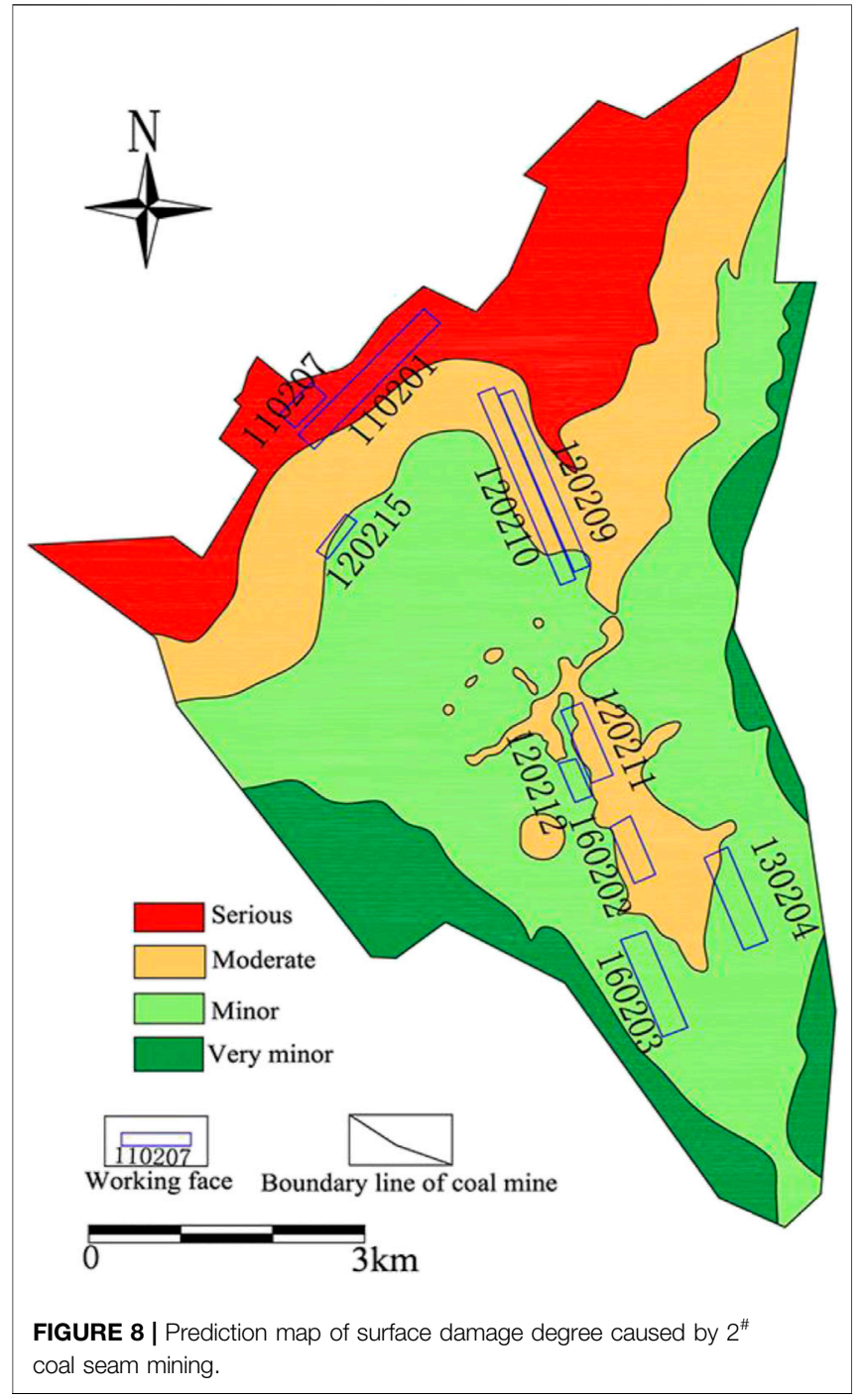

$$
x_{i}^{\prime}=\frac{x_{i}-\min x_{i}}{\max x_{i}-\min x_{i}}
$$

Equation 2:

$$
x_{i}^{\prime}=\frac{\max x_{i}-x_{i}}{\max x_{i}-\min x_{i}}
$$

where the $X_{i}$ ' was the dimensionless value, $X_{i}$ was the actual value of the $i$ factor, $\min X_{i}$ was the minimum value in the index value, and $\max X_{i}$ was the maximum value in the index value.

Furthermore, the value of the degree of surface damage $(W)$ was calculated using the prediction model. The calculated $\mathrm{W}$ values are in the range 0.1-0.9. After that, all $\mathrm{W}$ values were converted into ArcGIS 10.2 to produce the map of the degree of surface damage by $2 \#$ coal seam mining (Figure 8). Finally, the map was reclassified by the natural discontinuity method into four classes such as serious $(\mathrm{W}>0.7)$, moderate $(0.50<\mathrm{W}<0.7)$, minor $(0.0 .3<\mathrm{W}<0.5)$, and very minor $(0.10<\mathrm{W}<0.3)$. The area within $9.53 \mathrm{~km}^{2}$ of the northern boundary of the Yangchanwan Coal Mine was severe. The $14.41 \mathrm{~km}^{2}$ area in

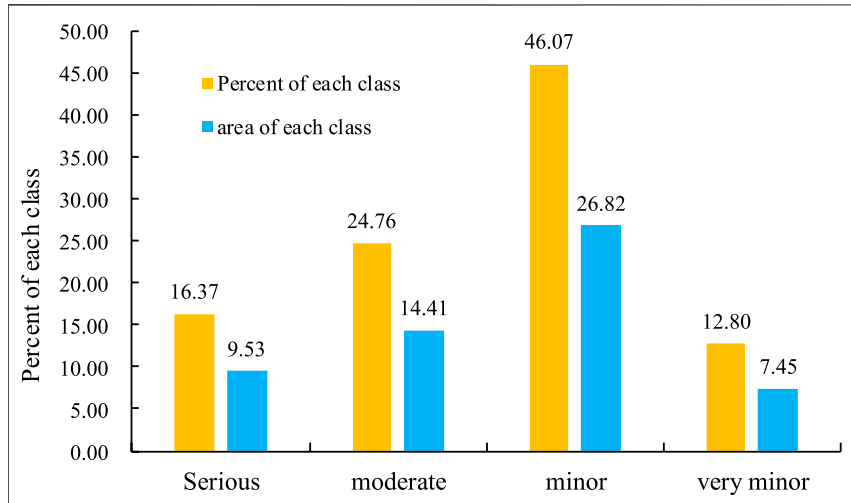

FIGURE 9 | Percentage of each class of the degree of surface damage.

TABLE 6 | Comparison of the degree of surface damage.

\begin{tabular}{lll}
$\begin{array}{l}\text { Names } \\
\text { of working face }\end{array}$ & Evaluation degree & Predicted degree \\
\hline 110,207 & Serious & Serious \\
110,201 & Serious & Serious \\
120,215 & Moderate & Moderate \\
120,210 & Moderate & Moderate \\
130,204 & Moderate & Moderate \\
160,203 & Moderate & Minor \\
120,212 & Minor & Minor \\
160,202 & Minor & Moderate
\end{tabular}

the north and the middle was a moderately damaged area of surface damage. Meanwhile, due to the influence of folds and faults, some of the middle areas were striped and slightly scattered. The remaining parts were the minor area and very minor area. The area percentages of each class are shown in Figure 9. The minor class has the largest area (46.07\%), followed by moderate $(24.76 \%)$, serious $(16.37 \%)$, and very minor $(12.80 \%)$.

\section{Validation of Prediction Results}

The 8 usable working faces investigated in this study were added to the map of the degree of surface damage caused by $2^{\#}$ coal seam mining by using the back substitution method. In the 8 working faces, the degree of surface damage obtained by the prediction was basically consistent with the level of the evaluation, and the accuracy was $87.5 \%$ (Table 6), indicating that this method can be used for the prediction of the degree of surface damage induced by coal mining.

\section{DISCUSSION}

As an important part of the whole ecological environment in the coal mine, the surface ecological environment is bound to undergo negative changes due to coal mining. Especially in Northwest China, the impact of coal mining on the surface ecological environment is more serious. According to the 
statistics, the total surface collapse area has exceeded 1,189 ha (Shang, 2013) in Lingwu mining area caused by large-scale coal mining, resulting in a continuous decline in the quality of the surface ecological environment. Thus, it is necessary to accurately evaluate the impact of coal mining on the surface environment based on determining the form and degree of surface damage. In this study, the surface damage degree and the classification standard were established. However, this evaluation system is only aimed at surface damage and is the basis of surface ecological environment assessment. Therefore, the evaluation system of vegetation and surface water resources needs to be constructed in the follow-up research, and then improve the evaluation system of the impact of coal mining on the surface ecological environment.

Several reports have shown that the surface damage caused by coal mining is a complex process, which can be summarized as two stages: rock collapse and topsoil deformation (Chen and $\mathrm{Hu}$., 2018). In the stage of rock collapse, the overlying rock mass will subside and collapse under the action of gravity. In the stage of topsoil deformation, the movement and deformation of topsoil will damage the integrity of the surface. Surface damage mainly includes surface collapse, surface cracks, surface subsidence, and associated disasters, among which, surface cracks are the most common type of surface damage in the coal mine area. Different from the previous research results in using surface deformation parameters ( $Y u$, et al., 2008; Zou, et al., 2003) to evaluate the degree of surface damage caused by coal mining, we selected surface cracks, associated disasters, and buildings as the basis for dividing the degree of surface damage, which reduces the difficulty of obtaining the characteristic data of the evaluation index.

There are many factors affecting the degree of surface damage caused by coal mining, which can be divided into three categories: coal mining, geology, and geomorphology (Hu, et al., 2014b). Therefore, the prediction of mining surface damage degree is a multi-disciplinary and complex research field, which needs to be combined with different data sources to predict the degree of surface damage. In this study, six conditioning factors were selected as prediction factors, and the prediction model of surface damage degree is constructed by the AHP method. Through superposition analysis, the prediction map of surface damage degree of $2^{\#}$ coal seam in the Yangchangwan Coal Mine was obtained. The minor class has the largest area $(46.07 \%)$, followed by moderate $(24.76 \%)$, serious $(16.37 \%)$, and very minor $(12.80 \%)$, and the overall accuracy is $87.5 \%$ (Table 6). However, in addition to the influencing factors discussed in this paper, the surface damage induced by coal mining is also related to the coal mining process, mining speed, working face layout, the nature of overlying bedrock, rainfall, and topography, and the control effect of each factor on the surface damage needs to be further studied. In addition, the prediction model of the surface damage degree constructed in this paper is relatively simple and does not involve more predictive factors such as multi-coal seam mining conditions, topography, lithology, and so on. The treatment method for structural geological conditions is relatively simple, so it is necessary to construct a complex prediction model covering multiple factors in future research.

\section{CONCLUSION}

(1) Based on the results of the surface damage investigation, the degree and the classification standard were established with these factors including the crack density, maximum drop of crack, maximum width, maximum subsidence, the associated disasters, and other features. The degree was divided into four grades such as serious, moderate, minor, and very minor. Meanwhile, the evaluation method and process of surface damage degree by mining of the working face were given.

(2) In this research, the AHP model was systematically analyzed for application in the prediction of surface damage caused by coal mining. Six factors were extracted for the study including ratio of the buried depth to the thickness of the coal seam $(\mathrm{H} /$ $\mathrm{M})$, ratio of the thickness of overlying bedrock to the thickness of the coal seam $(\mathrm{Hj} / \mathrm{M})$, thickness of the loose layer (Ms), geomorphology, distance to faults, and distance to folds, and the weights for these factors were calculated, which were $0.271,0.453,0.121,0.072,0.052$, and 0.031 .

(3) According to the predicted result of the degree of surface damage by $2^{\#}$ coal seam mining, four groups such as serious, moderate, minor, and very minor were reclassified by the natural discontinuity method, and the minor class has the largest area, followed by moderate, serious, and very minor. The verification result of the back-substitution method shows that the AHP model has an accuracy rate of 0.875 . Finally, these study results may be useful for protection of the ecology.

\section{DATA AVAILABILITY STATEMENT}

The original contributions presented in the study are included in the article/Supplementary Material, further inquiries can be directed to the corresponding authors.

\section{AUTHOR CONTRIBUTIONS}

$\mathrm{XX}$ and $\mathrm{EH}$ provided all the basic data of this manuscript, determined the research ideas and methods, discussed the related research progress, and wrote this manuscript. TL collected data on surface cracks by UAV aerial photography. $\mathrm{XX}, \mathrm{DF}$, and PH completed the calculation based on AHP. QW, YL, and JL provided the basic maps and borehole data of the study area.

\section{FUNDING}

This research was supported by the National Natural Science Foundation of China (No. 42177174), the Basic Research Program of Natural Science of Shaanxi Province (2020ZY-JC03), and the Shannxi Province Joint Fund Project (2021JLM-09), major projects supported by Shaanxi Coal Chemical Group Co., Ltd. (2018SMHKJ-A-J-03). 


\section{REFERENCES}

Bell, F. G., Stacey, T. R., and Genske, D. D. (2000). Mining Subsidence and its Effect on the Environment: Some Differing Examples. Environ. Geology. 40 (1), 135-152. doi:10.1007/s002540000140

Chen, C., and $\mathrm{Hu}, \mathrm{Z}, \mathrm{Q}$. (2018). Research Advances in Formation Mechanism of Ground Crack Due to Coal Mining Subsidence in China. J. China Coal Soc. 43 (3), 810-823. doi:10.13225/ j.cnki.jccs.2017.0942

Djamaluddin, I., Mitani, Y., and Esaki, T. (2011). Evaluation of Ground Movement and Damage to Structures from Chinese Coal Mining Using a New GIS Coupling Model. Int. J. Rock Mech. Mining Sci. 48 (3), 380-393. doi:10.1016/j.ijrmms.2011.01.004

Durmuşoğlu, Z. D. U. (2018). Assessment of Techno-Entrepreneurship Projects by Using Analytical Hierarchy Process (AHP). Tech. Soc. 54, 41-46. doi:10.1016/ j.techsoc.2018.02.001

Fan, L. M., Ma, X. D., Li, Y. H., Li, C., Yao, C. W., Xiang, M. X., et al. (2017). Geological Disasters and Control Technology in High Intensity Mining Area of Western China (In Chinese). J. China Coal Soc. 42 (2), 276-285. doi:10.13225/ j.cnki.jccs.2016.6002

Fan, L, M., Zhang, X, T., Xiang, M, X., Zhang, H, Q., Shen, T., and Lin, P, X. (2015). Characteristics of Ground Fissure Development in High Intensity Mining Area of Shallow Seam in Yushenfu Coal Field (In Chinese). J. China Coal Soc. 40 (6), 1442-1447. doi:10.13225/j.cnki.jccs.2014.1707

Feng, Y, L., and Luo, Q. W. (2016). The Risk Evaluation for Goaf Surface Subsidence Based on Rough Set (In Chinese). J. Henan Polytechnic Univ. (Natural Science) 35 (6), 759-764.

Gnanavelbabu, A., and Arunagiri, P. (2018). Ranking of MUDA Using AHP and Fuzzy AHP Algorithm. Mater. Today Proc. 5 (5), 13406-13412. doi:10.1016/ j.matpr.2018.02.334

Guo, W, B., Guo, M, J., Tan, Y., Bai, E, H., and Zhao, G, B. (2019). Sustainable Development of Resources and the Environment: Mining-Induced EcoGeological Environmental Damage and Mitigation Measures-A Case Study in the Henan Coal Mining Area, China. Sustainability 11 (16), 4366. doi: $10.3390 /$ su11164366

Hu, Z, Q., Wang, X, J., and He, A, M. (2014b). Distribution Characteristic and Development Rules of Ground Fissures Due to Coal Mining in Windy and sandy Region (In Chinese). J. China Coal Soc. 39 (1), 11-18. doi:10.13225/ j.cnki.jccs.2013.1289

Hu, Z., Yang, G., Xiao, W., Li, J., Yang, Y., and Yu, Y. (2014a). Farmland Damage and its Impact on the Overlapped Areas of Cropland and Coal Resources in the Eastern plains of China. Resour. Conservation Recycling 86, 1-8. doi:10.1016/ j.resconrec.2014.01.002

Huang, F., Zhu, H., Xu, Q., Cai, Y., and Zhuang, X. (2013). The Effect of Weak Interlayer on the Failure Pattern of Rock Mass Around Tunnel - Scaled Model Tests and Numerical Analysis. Tunnelling Underground Space Tech. 35, 207-218. doi:10.1016/j.tust.2012.06.014

Kim, K.-D., Lee, S., and Oh, H.-J. (2009). Prediction of Ground Subsidence in Samcheok City, Korea Using Artificial Neural Networks and GIS. Environ. Geol. 58 (1), 61-70. doi:10.1007/s00254-008-1492-9

Lee, S., Park, I., and Choi, J.-K. (2012). Spatial Prediction of Ground Subsidence Susceptibility Using an Artificial Neural Network. Environ. Manag. 49 (2), 347-358. doi:10.1007/s00267-011-9766-5

Li, X. J., Shao, F., Li, J., and Liu, X. (2012). Evaluation to Damage Situation of Coal Mining Subsidence Land in Mountainous Area Based on MSPS and GIS. Amr 518-523, 5692-5696. doi:10.4028/www.scientific.net/AMR.518523.5692

Malinowska, A., and Hejmanowski, R. (2010). Building Damage Risk Assessment on Mining Terrains in Poland with GIS Application. Int. J. Rock Mech. Mining Sci. 47 (2), 238-245. doi:10.1016/j.ijrmms.2009.09.009

Quanyuan, W., Jiewu, P., Shanzhong, Q., Yiping, L., Congcong, H., Tingxiang, L., et al. (2009). Impacts of Coal Mining Subsidence on the Surface Landscape in Longkou City, Shandong Province of China. Environ. Earth Sci. 59 (4), 783-791. doi:10.1007/s12665-009-0074-9
Rezaei, M., Yazdani Noori, Z., and Dashti Barmaki, M. (2020). Land Subsidence Susceptibility Mapping Using Analytical Hierarchy Process (AHP) and Certain Factor (CF) Models at Neyshabur plain, Iran. Geocarto Int. 2020, 1-17. doi:10.1080/10106049.2020.1768596

Saaty, T. L. (1980). The Analytical Hierarchy Process. New York: McGraw Hill.

Shang, H. (2013). Assessment and Dynamic Monitoring of Mining GeoEnvironment in Ningxia. Beilin: Chang' an University.

Shao, L. (2019). Geological Disaster Prevention and Control and Resource protection in mineral Resource Exploitation Region. Int. J. Low-Carbon Tech. 14 (2), 142-146. doi:10.1093/ijlct/ctz003

Si, H., Bi, H., Li, X., and Yang, C. (2010). Environmental Evaluation for Sustainable Development of Coal Mining in Qijiang, Western China. Int. J. Coal Geology. 81, 163-168. doi:10.1016/j.coal.2009.11.004

Wang, S, M., Sun, Q., Qiao J, W., and Wang, S. Q. (2020). Geological Guarantee of Coal green Mining. J. China Coal Soc. 45 (1), 8-15. doi:10.13225/ j.cnkijccsYG191758

Xiao, W., Lv, X., Zhao, Y., Sun, H., and Li, J. (2020). Ecological Resilience Assessment of an Arid Coal Mining Area Using index of Entropy and Linear Weighted Analysis: A Case Study of Shendong Coalfield, China. Ecol. Indicators 109, 105843. doi:10.1016/j.ecolind.2019.105843

Xie, X., Hou, E., Wang, S., Sun, X., Hou, P., Wang, S., et al. (2021). Formation Mechanism and the Height of the Water-Conducting Fractured Zone Induced by Middle Deep Coal Seam Mining in a Sandy Region: A Case Study from the Xiaobaodang Coal Mine. Adv. Civil Eng. 2021, 1-11. doi:10.1155/2021/6684202

Xu, J., Zhao, H., Yin, P., Wu, L., and Li, G. (2019b). Landscape Ecological Quality Assessment and its Dynamic Change in Coal Mining Area: a Case Study of Peixian. Environ. Earth Sci. 78 (24), 1-13. doi:10.1007/s12665019-8747-5

Xu, Y., Wu, K., Li, L., Zhou, D., and Hu, Z. (2019a). Ground Cracks Development and Characteristics of Strata Movement under Fast Excavation: a Case Study at Bulianta Coal Mine, China. Bull. Eng. Geol. Environ. 78 (1), 325-340. doi:10.1007/s10064-017-1047-y

Yan, W., Dai, H., and Chen, J. (2018). Surface Crack and Sand Inrush Disaster Induced by High-Strength Mining: Example from the Shendong Coal Field, china. Geosci. J. 22 (2), 347-357. doi:10.1007/s12303-017-0031-7

Yan, Y., Yan, W., Dai, H., and Guo, J. (2021). Distribution Characteristics and Formation Mechanism of Surface Crack Induced by Extrathick Near Horizontal Seam Mining: An Example from the Datong Coal Field, China. Adv. Civil Eng. 2021, 1-10. doi:10.1155/2021/5545128

Yu, X. Y., Li, B. B., Li, R. B., Duan, W. S., and Liu, P. L. (2008). Analysis of Mining Damage in Huge Thick Collapsible Loess of Western China (In Chinese). J. China Univ. Mining Tech. 37 (1), 43-47.

Zeng, W., Huang, Z., Wu, Y., Li, S., Zhang, R., and Zhao, K. (2020). Experimental Investigation on Mining-Induced Strain and Failure Characteristics of Rock Masses of Mine Floor. Geomatics, Nat. Hazards Risk 11 (1), 491-509. doi:10.1080/19475705.2020.1734102

Zhang, J., Zhang, Q., Zhao, C., and Qu, F, F. (2011). "The Sensitivity Evaluation of Ground Fissures in Yuncheng, Shanxi, China with GIS and AHP Method," in 2011 19th International Conference on Geoinformatics, Shanghai, China, June 24-26, 2011 (IEEE), 1-6. doi:10.1109/geoinformatics.2011.5981011

Zhang, Z. S., and Sui, W, H. (2017). An Evaluation Model for Geological Environmental Impact of Coal Mines in Xinjiang (In Chinese). J. China Coal Soc. 42 (2), 344-352. doi:10.13225/j.cnki.jccs.2016.6011

Zhu, H., He, F., and Fan, Y. (2018). Development Mechanism of Mining-Induced Ground Fissure for Shallow Burial Coal Seam in the Mountains Area of Southwestern China: a Case Study. Acta GeodynGeomater 15 (4), 349-362. doi:10.13168/AGG.2018.0026

Zou, Y, F., Deng, K, Z., and Ma, W, M. (2003). Mining Engineering Mining Subsidence Engineering. Xuzhou: China University of Mining and Technology press.

Conflict of Interest: Authors QW, YL, JL were employed by the company Ningxia Coal Industry Co., Ltd. 
The remaining authors declare that the research was conducted in the absence of any commercial or financial relationships that could be construed as a potential conflict of interest.

The authors declare that this study received funding from Shaanxi Coal Chemical Group Co., Ltd. The funder was not involved in the study design, collection, analysis, interpretation of data, the writing of this article or the decision to submit it for publication.

Publisher's Note: All claims expressed in this article are solely those of the authors and do not necessarily represent those of their affiliated organizations, or those of the publisher, the editors and the reviewers. Any product that may be evaluated in this article, or claim that may be made by its manufacturer, is not guaranteed or endorsed by the publisher.

Copyright (C) 2022 Xie, Hou, Long, Feng, Hou, Wei, Li and Liu. This is an open-access article distributed under the terms of the Creative Commons Attribution License (CC $B Y)$. The use, distribution or reproduction in other forums is permitted, provided the original author(s) and the copyright owner(s) are credited and that the original publication in this journal is cited, in accordance with accepted academic practice. No use, distribution or reproduction is permitted which does not comply with these terms. 